AperTO - Archivio Istituzionale Open Access dell'Università di Torino

\title{
Enhanced PAHs adsorption using iron-modified coal-based activated carbon via microwave radiation
}

\section{This is the author's manuscript}

Original Citation:

Availability:

This version is available http://hdl.handle.net/2318/1637317

since 2017-07-13T17:54:08Z

Published version:

DOI:10.1016/j.jtice.2016.03.050

Terms of use:

Open Access

Anyone can freely access the full text of works made available as "Open Access". Works made available under a Creative Commons license can be used according to the terms and conditions of said license. Use of all other works requires consent of the right holder (author or publisher) if not exempted from copyright protection by the applicable law. 
This Accepted Author Manuscript (AAM) is copyrighted and published by Elsevier. It is posted here by agreement between Elsevier and the University of Turin. Changes resulting from the publishing process - such as editing, corrections, structural formatting, and other quality control mechanisms - may not be reflected in this version of the text. The definitive version of the text was subsequently published in JOURNAL OF THE TAIWAN INSTITUTE OF CHEMICAL ENGINEERS, 64, 2016, 10.1016/j.jtice.2016.03.050.

You may download, copy and otherwise use the AAM for non-commercial purposes provided that your license is limited by the following restrictions:

(1) You may use this AAM for non-commercial purposes only under the terms of the CC-BY-NC-ND license.

(2) The integrity of the work and identification of the author, copyright owner, and publisher must be preserved in any copy.

(3) You must attribute this AAM in the following format: Creative Commons BY-NC-ND license (http://creativecommons.org/licenses/by-nc-nd/4.0/deed.en), 10.1016/j.jtice.2016.03.050

The publisher's version is available at:

http://linkinghub.elsevier.com/retrieve/pii/S187610701630044X

When citing, please refer to the published version.

Link to this full text:

http://hdl.handle.net/2318/1637317 


\section{Enhanced PAHs adsorption using iron-modified coal-based} activated carbon via microwave radiation

\author{
Xinyu Ge ${ }^{\mathrm{a}}$, Zhansheng Wu ${ }^{\mathrm{a}, \mathrm{b} *}$, Zhilin Wu ${ }^{\mathrm{b}}$, Yujun Yan ${ }^{\mathrm{a}}$, Giancarlo Cravotto ${ }^{\mathrm{b}}$, Bang-Ce \\ $\mathbf{Y e}^{\mathrm{a}}$ \\ ${ }^{a}$ School of Chemistry and Chemical Engineering, Shihezi University, Shihezi 832003, P.R. \\ China \\ ${ }^{b}$ Dipartimento di Scienza e Tecnologia del Farmaco, University of Turin, Torino 10125, Italy \\ Corresponding author: Zhansheng Wu, Shihezi University, Shihezi 832003, P.R. China. \\ Tel: 86993-2055015, Fax: 86993-2057270, E-mail address: wuzhans@126.com.
}




\section{ABSTRACT}

As an effective adsorbent, coal-based activated carbon (CAC) was modified with iron through microwave radiation to adsorb polycyclic aromatic hydrocarbons (PAHs) from aqueous solutions. The effects of iron nitrate concentration, microwave power, and microwave radiation time on CAC were investigated. The optimum modification conditions were as follows: iron nitrate concentration, $0.05 \mathrm{M}$; microwave power, $300 \mathrm{~W}$; and microwave radiation time, $5 \mathrm{~min}$ (designated as 0.05Fe-MCAC). CAC and 0.05Fe-MCAC were characterized using scanning electron microscopy, nitrogen adsorption-desorption, surface acidity and basicity tests, and Fourier transform infrared spectroscopy. The adsorption capacities of PAHs were also determined. After modification the following phenomena occurred: pore structures developed; BET surface area increased from 686.06 to $1079.67 \mathrm{~m}^{2} / \mathrm{g}$; the number of oxygen-containing groups decreased; and basicity was enhanced. The PAHs adsorption capacity of 0.05Fe-MCAC was higher than that of CAC. The altered texture and chemical properties of 0.05Fe-MCAC played an important role in PAHs adsorption. The pseudo-second-order models of CAC and 0.05Fe-MCAC fitted well. The PAHs adsorption of 0.05Fe-MCAC owned lower activation energy and greater stability than that of CAC. Results indicated that iron-modified CAC via microwave radiation is a promising and efficient adsorbent of PAHs from aqueous solutions.

Keywords Coal-based activated carbon · Microwave radiation · Iron modification · PAHs adsorption 


\section{Introduction}

Polycyclic aromatic hydrocarbons (PAHs) commonly refer to a large class of dangerous and harmful ecosystem pollutants. They are generated during the incomplete combustion of hydrocarbons and other organic compounds, such as coal, petroleum, and biomass [1, 2]. PAHs can be transported in long distances in water but cannot be easily biodegraded because of their chemical persistence and semi-volatile nature [3]. In addition their toxic, mutagenic, and carcinogenic properties, they are considered as priority pollutants [4]. PAHs are effectively removed from aqueous solutions through adsorption [5, 6]. Nevertheless, economical and applicable absorbents should be developed to remove PAHs efficiently.

Activated carbon (AC) is characterized by a wide surface area and developed porosity; as such, it is considered a highly promising absorbent for a wide range of technical applications [6-8]. AC is also a commonly used adsorbent in wastewater treatments worldwide. AC is modified to regulate its pore structure and chemical properties. This process is an effective route to enhance the removal efficiency of AC as an adsorbent of various pollutants. Liu et al. [9] modified bamboo-based AC and found that the modified AC can effectively adsorb methylene blue. Shaarani et al. [10] demonstrated that ammonia-modified AC for adsorption of 2, 4-dichlorophenol was superior to the AC. Yin et al. [11] also modified AC-enhanced contaminant uptake from aqueous solutions. However, coal-based AC (CAC) has been rarely developed as an absorbent of PAHs from aqueous solutions [12-14]. Other materials are also more commonly used than CAC. Organic compound adsorption by AC is generally influenced by various properties, such as pore size, pore diameter distribution, surface properties, and surface functional groups $[15,16]$. 
Therefore, structure and surface functional groups should be appropriately controlled to improve the adsorption of PAHs from aqueous solutions.

Metal-modified AC may provide an enhanced porosity structure and can vary in terms of pore structure and surface functional groups; thus, adsorption properties are altered [17]. Various metal oxides, such as manganese, mercury, and iron, have been added to AC to improve their adsorption performance [18-20]. However, iron-modified CAC used for the adsorption of PAHs from aqueous solutions has yet to be reported. Microwave is currently used in various fields to heat dielectric materials because this technique requires a considerably short treatment time and consumes low energy. In our previous study, microwave radiation can change the physical properties of AC [14]. Thus, iron-modified CAC via microwave radiation should be investigated to enhance the adsorption of PAHs.

This study aimed to modify CAC with iron via microwave radiation and to investigate the properties of the modified CAC and its adsorption capacities for PAHs from aqueous solutions. CAC and 0.05Fe-MCAC were characterized through scanning electron microscopy (SEM), nitrogen adsorption-desorption, surface acidity and basicity, and Fourier transform infrared spectroscopy (FTIR) methods. The adsorption capacity of naphthalene on 0.05Fe-MCAC was also examined, and the adsorption kinetics of PAHs on CAC and 0.05Fe-MCAC were systematically analyzed. PAHs adsorption on CAC and 0.05Fe-MCAC were compared, and the correlation of this property with their structures was determined. This work could evaluate the effectiveness of 0.05Fe-MCAC in the removal of PAHs from aqueous solutions and could enhance our understanding of the adsorption behavior of PAHs onto 0.05Fe-MCAC. 


\section{Materials and methods}

\subsection{Preparation of CAC}

Coal-based activated carbon (CAC) was prepared according to our previous study [21], where the used coal (Xinjiang Tebian Electric Apparatus Stock Co., Ltd, China) was activated using potassium hydroxide under microwave radiation. Microwave radiation was conducted in a $2.45 \mathrm{GHz}$ microwave oven (MM823LA6-NS, Midea). The preparation conditions of CAC were as follows: hydroxide potassium-to-coal ratio (w/w), 1:1; microwave power, $700 \mathrm{~W}$; and radiation time, $10 \mathrm{~min}$. The obtained products were in an air-dried oven at $110{ }^{\circ} \mathrm{C}$ for $4 \mathrm{~h}$ and marked as CAC. All of the chemicals and reagents used in this study were of analytical grade.

\subsection{Modification of iron nitrate via microwave radiation}

In this study, $0.2 \mathrm{~g}$ of CAC absorbent was added to a $150 \mathrm{~mL}$ conical flask with $15 \mathrm{~mL}$ of different concentrations $(0.05-1 \mathrm{M})$ of $\mathrm{Fe}\left(\mathrm{NO}_{3}\right)_{3}$ solution, and ultrasound was conducted for $2 \mathrm{~h}$. The mixture was heated in a microwave oven (MCR-3, Shanghai Keli) at microwave power of $100-700 \mathrm{~W}$ and microwave radiation times of 1-8 min. After modification treatment, the mixture was filtered and extensively washed with double distilled water and dried in an oven at $110^{\circ} \mathrm{C}$ for $4 \mathrm{~h}$. These samples were named as Fe-MCAC and $0.05 \mathrm{M}$ of $\mathrm{Fe}\left(\mathrm{NO}_{3}\right)_{3}$-modified sample was designated as 0.05 Fe-MCAC.

\subsection{Characterization of CAC and 0.05Fe-MCAC}

\subsubsection{SEM}

The morphologies of carbon samples were observed on scanning electron microscopy (SEM, JEOL, JSM-6490LV, Japan) with an acceleration voltage of $15 \mathrm{kV}$. Prior to analysis, 
111 the samples were dried at $383 \mathrm{~K}$ and stored in a desiccator overnight.

112 2.3.2. Fourier transform infrared (FTIR) spectrometer

For FTIR measurements, the CAC and 0.05Fe-MCAC samples were blended with $\mathrm{KBr}$

114 to form pellets; the spectra were obtained on a PHI5700 ESCA spectrophotometer in the 115 range of $4000-400 \mathrm{~cm}^{-1}$ at $4 \mathrm{~cm}^{-1}$ resolution.

116 2.3.3. BET surface area and pore structure analysis

117 The Brunauer-Emmett-Teller (BET) surface area and porous properties of the CAC and 118 0.05Fe-MCAC samples were determined from the $\mathrm{N}_{2}$ adsorption at $77 \mathrm{~K}$ using a surface 119 area analyzer (SI/MP, Quantachrome, USA).

$120 \quad$ 2.3.4. Surface acidity and basicity

The amphoteric characteristics of the CAC and 0.05Fe-MCAC samples were characterized by measuring the amount of the surface functional groups using the acid-base titration method proposed by Boehm [22]. According to this method and our reported studies [14, 22], $200 \mathrm{mg}$ of each sample was added to $25 \mathrm{~mL}$ solutions of $0.05 \mathrm{M}$ : sodium hydroxide, sodium carbonate, sodium bicarbonate and hydrochloric acid, respectively. The mixture was oscillated for $24 \mathrm{~h}$ in constant temperature vibrator at $25^{\circ} \mathrm{C}$, and the resulting suspensions were filtered for estimating the residual base/acid.

\subsection{Adsorption test}

\subsubsection{Adsorption of PAHs from aqueous solution}

Naphthalene, phenanthrene, pyrene were selected as the typical compounds, which are commonly exist in wastewater/soil mediums. $15 \mathrm{mg}$ of the carbon samples were added into

132 flask containing $100 \mathrm{~mL}, 30.0 \mathrm{mg} / \mathrm{L}$ of naphthalene, phenanthrene, and pyrene solution at 
$144 \quad q_{\mathrm{t}}=\frac{\left(C_{0}-C_{\mathrm{t}}\right) \times V}{m}$

$20{ }^{\circ} \mathrm{C}$, respectively. After agitation for $60 \mathrm{~min}$, the mixture solution was filtered, and naphthalene, phenanthrene, and pyrene concentrations were measured using a UV-75N spectrophotometer at $218 \mathrm{~nm}, 248 \mathrm{~nm}$ and $237 \mathrm{~nm}$, respectively. The amounts of naphthalene, phenanthrene, and pyrene on samples were calculated using the average of the three data.

\subsubsection{Adsorption kinetic}

Naphthalene, phenanthrene, and pyrene adsorption kinetics were evaluated at 10, 20, 30, and $40{ }^{\circ} \mathrm{C}$, respectively. The initial concentration was set as $30 \mathrm{mg} / \mathrm{L}$, and the samples were reacted at different contacting time intervals. The mixture was separated through filtration. Naphthalene, phenanthrene, and pyrene concentrations were determined using a UV-75N spectrophotometer. The amounts of naphthalene, phenanthrene, and pyrene at time $\mathrm{t}(\mathrm{min}), q_{t}$ (mg/g), can be calculated according to Eq. (1),

where $C_{\mathrm{t}}(\mathrm{mg} / \mathrm{L})$ is the liquid-phase concentration of naphthalene, phenanthrene, and pyrene at any time t, respectively.

\subsection{Regeneration of spent carbon}

The 0.05Fe-MCAC adsorbed pyrene sample was desorbed and immersed in $100 \mathrm{~mL}$ absolute ethanol for $90 \mathrm{~min}$. The carbon sample was removed and dried in vacuum at $110^{\circ} \mathrm{C}$ for $24 \mathrm{~h}$. The regeneration of carbon was determined, and the pyrene adsorption capacity was calculated repeatedly by using the described adsorption method. Desorption experiments were conducted again using the same adsorption method, and the cycle was repeated thrice.

\section{Results and discussion}

\subsection{Adsorption capacity of Fe-MCAC for naphthalene}




\subsubsection{Effects of iron nitrate solution concentrations}

We investigated the effects of the concentration of iron nitrate solution on the preparation of Fe-MCAC for naphthalene adsorption under the same microwave radiation conditions (Fig. 1). As the concentration of iron nitrate solution increased, the amount of naphthalene adsorbed on Fe-MCAC gradually decreased. The 0.05Fe-MCAC sample modified with $0.05 \mathrm{M}$ iron nitrate solution yielded a maximum adsorption capacity of 159.00 $\mathrm{mg} / \mathrm{g}$, which was significantly higher than the adsorption capacity of the CAC sample (95.74 $\mathrm{mg} / \mathrm{g})$. The $\mathrm{Fe}^{3+}$ modification influenced the adsorption capacity of the adsorbent possibly because of the change in texture and chemical properties on the surface of the CAC sample. Iron modification could enrich the pore structure of the Fe-MCAC sample, which enhanced the adsorption capacity of Fe-MCAC for naphthalene [17]. However, a high iron nitrate concentration was disadvantageous for the modified CAC for naphthalene adsorption in this study because excessive amounts of iron could be blocked pore of Fe-MCAC; as a consequence, a small pore volume is obtained, and the adsorption efficiency is decreased [20]. Considering that low concentration can save resources and enhance adsorption capacity, we selected $0.05 \mathrm{M}$ iron nitrate solution as the suitable modification concentration.

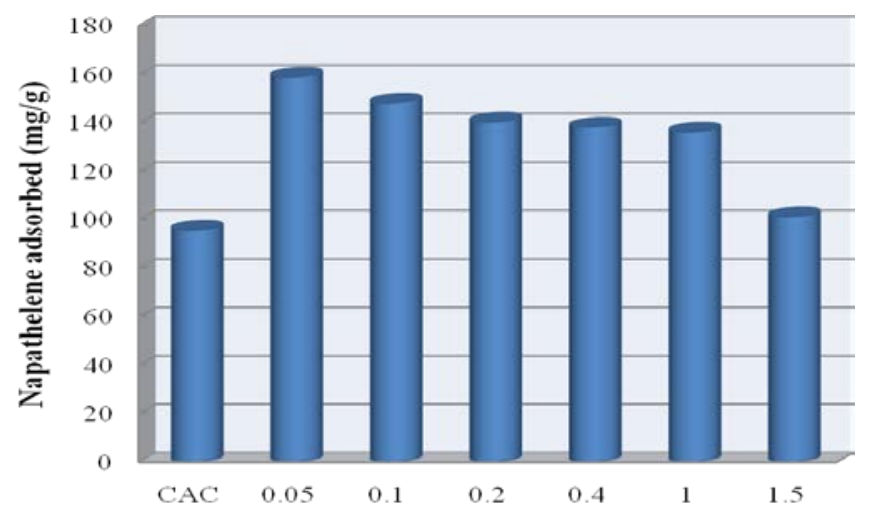

Iron nitrate solution concentration $(\mathrm{mol} / \mathrm{L})$

Fig. 1. Effects of iron nitrate solution concentrations on Fe-MCAC for naphthalene adsorption capacity (microwave power: $300 \mathrm{~W}$, microwave radiation time: $5 \mathrm{~min}$ ) 


\subsubsection{Effects of microwave power}

The effects of microwave power on the Fe-MCAC samples are presented in Fig. 2. The increased amounts of naphthalene adsorbed on the Fe-MCAC sample were higher than those on the CAC sample. As radiation power was enhanced to $300 \mathrm{~W}$, the amounts of naphthalene on the Fe-MCAC sample were maximized possibly because the pore structure on the surface of the Fe-MCAC sample was greatly developed at a radiation power of up to $300 \mathrm{~W}$. However, the adsorption capacity decreased from $172.18 \mathrm{mg} / \mathrm{g}$ to $128.48 \mathrm{mg} / \mathrm{g}$ as power was increased from $300 \mathrm{~W}$ to $900 \mathrm{~W}$. This result was due to the fierce reaction at high microwave power that reduces the surface area and porosity of the Fe-MCAC sample; as a consequence, the adsorption capacities of naphthalene were progressively decreased [23]. Hence, high microwave power is disadvantageous for the modified CAC. A microwave power of $300 \mathrm{~W}$ was the optimum modification condition.

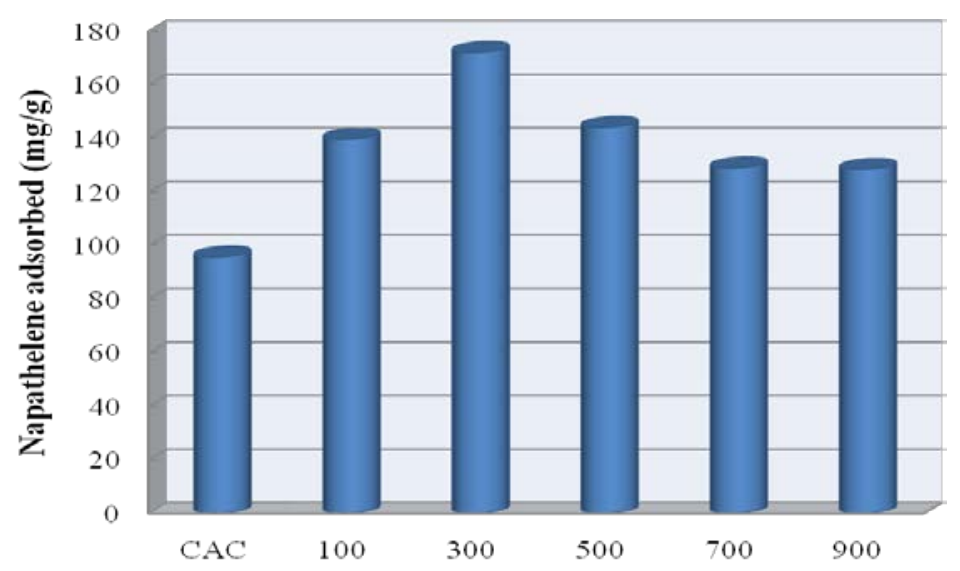

Microwave power (W)

Fig. 2. Effects of microwave power on Fe-MCAC for naphthalene adsorption capacity (iron nitrate: $0.05 \mathrm{M}$, microwave radiation time: $5 \mathrm{~min}$ )

\subsubsection{Effects of microwave radiation time}

The effect of microwave time on the preparation of Fe-MCAC can be observed by increasing radiation time from $1 \mathrm{~min}$ to $5 \mathrm{~min}$, which showed an enhancement of 
naphthalene capacity from $124.03 \mathrm{mg} / \mathrm{g}$ to $172.80 \mathrm{mg} / \mathrm{g}$. Beyond the value of $5 \mathrm{~min}$, the modified CAC obtained a lower naphthalene capacity (Fig. 3). A prominent drop was observed at 6 min probably as a result of a longer radiation time effect, which largely destroyed the pore walls between adjacent pores [24]. The results present that $5 \mathrm{~min}$ is the suitable period of time for modification because it provided the maximum naphthalene capacity with a value of $172.80 \mathrm{mg} / \mathrm{g}$.

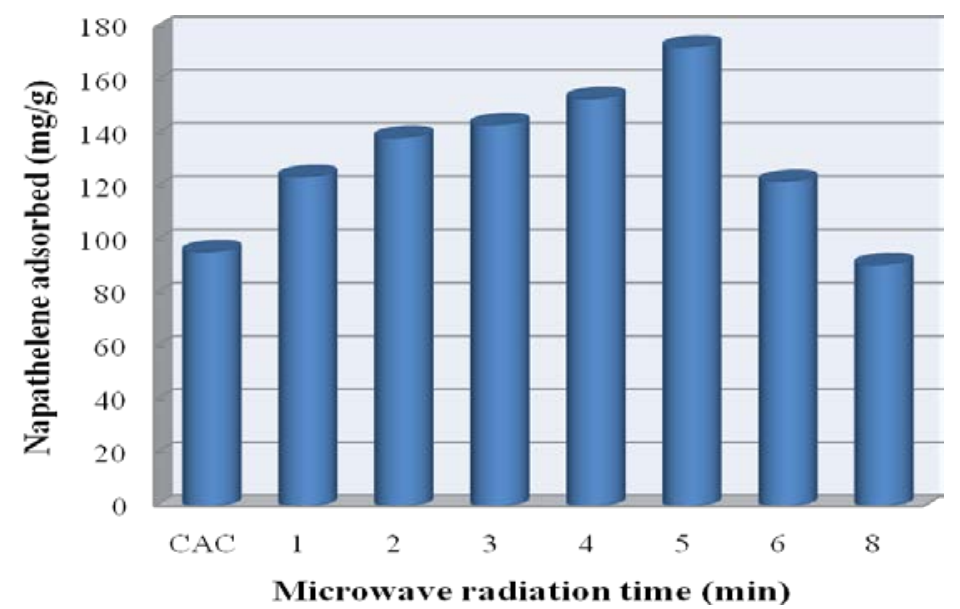

Fig. 3. Effects of microwave radiation time on Fe-MCAC for naphthalene adsorption capacity (iron nitrate: $0.05 \mathrm{M}$, microwave power: 300W)

From the discussion above, both iron nitrate solution concentration and microwave power had significant effects on the modified CAC for adsorption of naphthalene. The optimum conditions obtained were as follows: iron nitrate solution concentration $0.05 \mathrm{M}$, microwave power $300 \mathrm{~W}$, and microwave time $5 \mathrm{~min}$.

\subsection{Characterization}

\subsubsection{SEM}

The morphologies of the CAC and 0.05Fe-MCAC samples were carried out by SEM. The pore size distribution of the CAC sample with high magnifying power $(\times 1000)$ is uneven and exhibits less pores (Fig. 4). After iron modification treatment under microwave 
210 irradiation, the surface of the 0.05Fe-MCAC sample was more porous than that of CAC (Fig.

211 4). Iron ion has high activity and easily enters the pore of $0.05 \mathrm{Fe}-\mathrm{MCAC}$. Several studies

212 also showed that microwave radiation treatment effectively developed pores on the surface

213 of the CAC and AC, which greatly enlarged the surface area and porous structure of the

214 carbons $[14,25]$. Therefore, the developed porous structure could benefit the adsorption of

215 PAHs from aqueous solutions. In addition, 0.05Fe-MCAC can provide a large surface area

216 for iron loading; and iron surface has stronger activity and can better combine with the

217 adsorbate, which may promote $0.05 \mathrm{Fe}-\mathrm{MCAC}$ adsorption $[14,26]$. Chen et al. showed that

218 iron-impregnated AC was highly effective in arsenic removal [20]. Considering these factors,

219 the regulation of the pore structure of $\mathrm{CAC}$ and $\mathrm{Fe}^{3+}$ loading are great of significance for

220 PAHs adsorption.
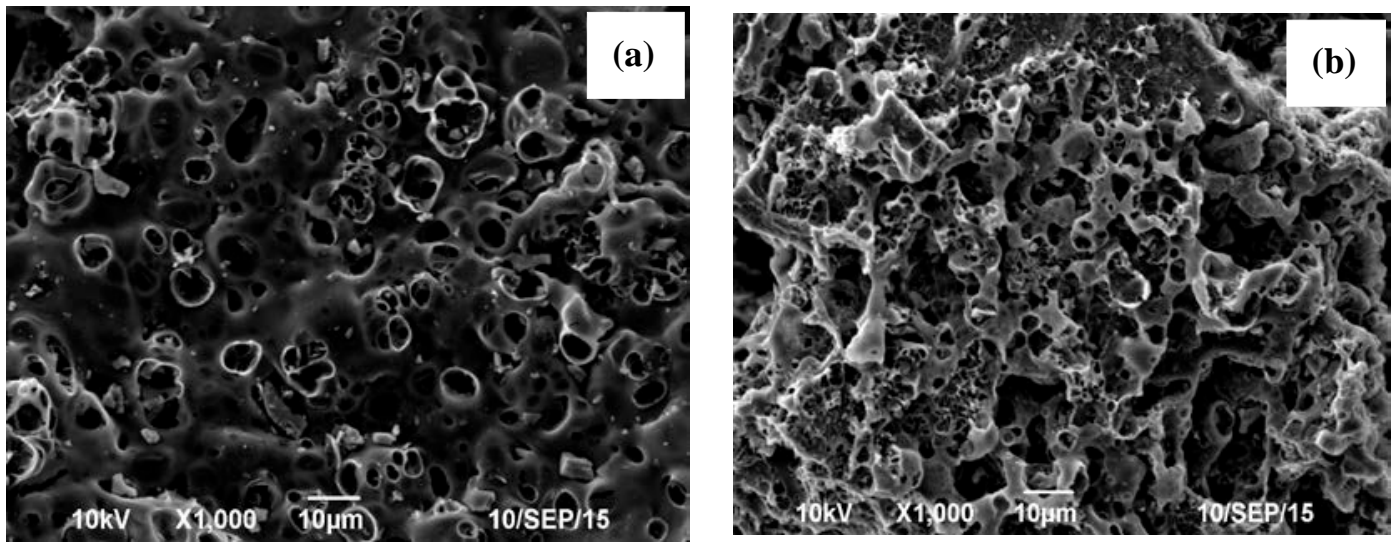

Fig. 4. Scanning electron microscope (SEM) micrograph: CAC (a); and 0.05Fe-MCAC (b)

\subsubsection{Fourier transform infrared (FTIR) spectrometer}

FTIR analysis permitted the spectrophotometric observation of the adsorbent surface in

224 the range of $400-4000 \mathrm{~cm}^{-1}$ and served as a direct means for identifying the organic

225 functional groups on the surface (Fig. 5). Insignificant changes, such as broadening of some

226 bands and spectral shifts, were observed in the FTIR spectrum of the 0.05Fe-MCAC 
$229-\mathrm{OH}$ stretching vibration $[17,20]$. The band at approximately $2920 \mathrm{~cm}^{-1}$ resulted from the

230 symmetric and asymmetric $\mathrm{C}-\mathrm{H}$ stretching vibrations [25]. The difference in the intensity of

231 the $1590 \mathrm{~cm}^{-1}$ between the two samples indicated that the modification process caused $\mathrm{C}=\mathrm{O}$

232 groups to decrease [25]. The peaks at approximately $1170 \mathrm{~cm}^{-1}$ represented the C-O

233 vibrations of various oxygen-containing groups. After iron modification, the

234 oxygen-containing functional group had a certain decrease. The most interesting changes in

235 the corresponding band were found at $485 \mathrm{~cm}^{-1}$, which could be attributed to the O-Fe

236 vibration. Rivera-Utrilla et al. also found this special band. This finding suggested that a

237 certain quantity of iron was loaded on the 0.05Fe-MCAC [27].

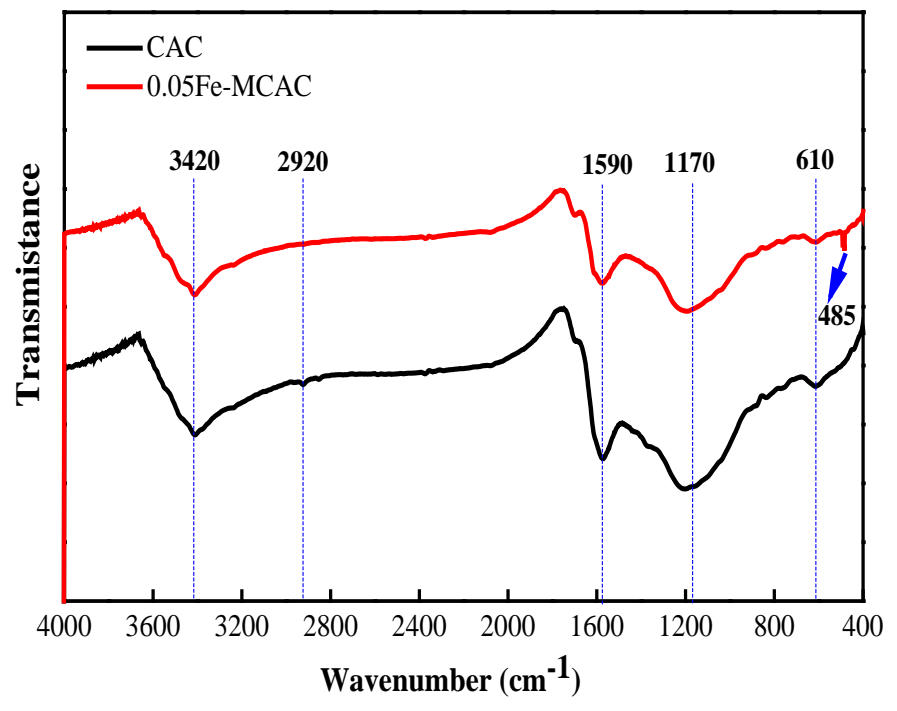

Fig. 5. FTIR analysis of the CAC and 0.05Fe-MCAC samples

3.2.3. Brunauer-Emmett-Teller (BET) surface area and pore structure analysis

The isotherms of the adsorption-desorption of $\mathrm{N}_{2}$ at $77 \mathrm{~K}$ were determined, as shown in

Fig. 6, to investigate the influence on the textural properties of the surfaces of the CAC and 

the CAC and 0.05Fe-MCAC samples were of type IV with a type- $\mathrm{H}_{4}$ hysteresis loop. This phenomenon has been reported in the scientific literature [14, 22]. These findings revealed a high portion of pores with indefinite pore size and shape in the 0.05Fe-MCAC particles [28]. The saturated adsorption amount of $\mathrm{N}_{2}$ was as follows: 0.05Fe-MCAC > CAC. Hence, the fixing of iron to $0.05 \mathrm{Fe}-\mathrm{MCAC}$ modified its textural characteristics. From the pore size analysis (Fig. 6), the two samples were essentially mesoporous because a vast majority of the pores ranged between 2 and $10 \mathrm{~nm}$. After iron modification, the average pore size of the
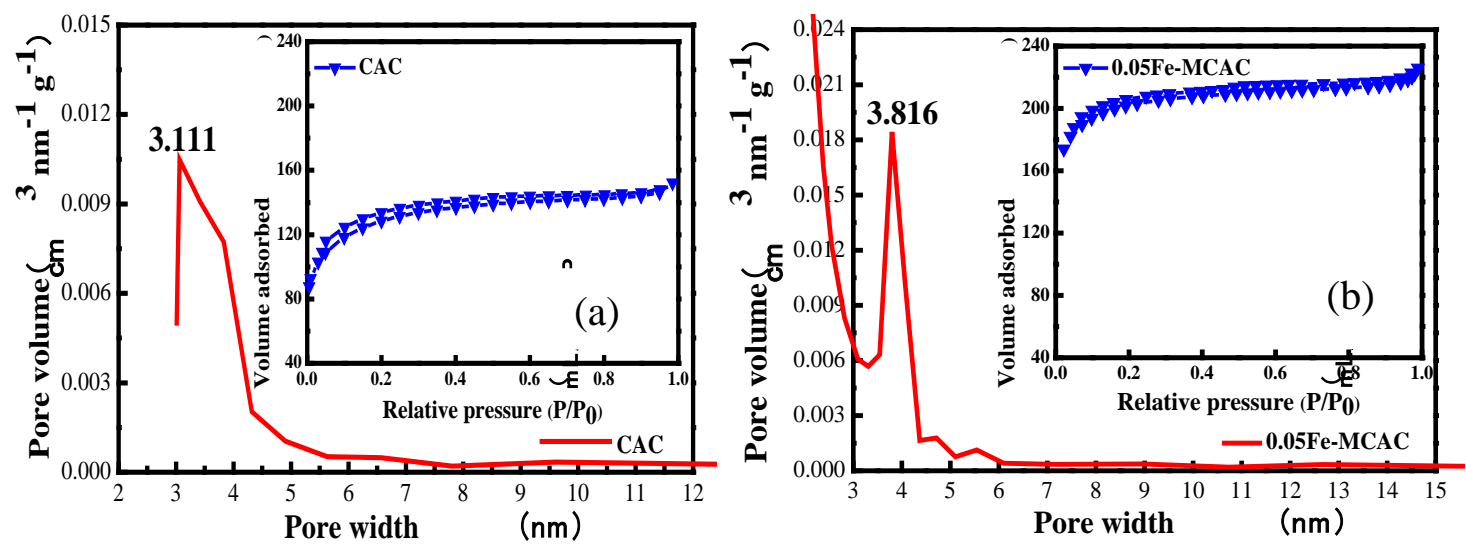

Fig. 6. Pore size distributions of CAC (a); and 0.05Fe-MCAC (b)

The pore characteristics of the CAC and 0.05Fe-MCAC samples based on the $\mathrm{N}_{2}$ adsorption-desorption isotherms are shown in Table 1. The BET surface area, mesopore surface area, external specific surface area, total pore volume, and mesoporous pore volume increased after modification with iron nitrate solution, which could enhance the adsorption efficiency for PAHs adsorption. Moreno-Piraján et al. [17] found that the AC from bamboo waste modified with iron increased the BET surface area from 985.00 to $1357.00 \mathrm{~m}^{2} / \mathrm{g}$ 
enhanced the adsorption for arsenite and arsenate. Ponvel et al. [28] showed that the metal ion modification of AC developed pore properties, and the removal of 2, 4-dichlorophenol

263 from aqueous solutions became more effective. Therefore, the loading of iron via microwave 264 radiation could enlarge pores and consequently form mesopores [29]. We accordingly speculated that the formed mesopores and developed pore properties could 266 benefit PAHs adsorption.

\section{Table 1}

268 BET analysis for CAC and 0.05Fe-MCAC

\begin{tabular}{lrc}
\hline Physical parameters & \multicolumn{1}{c}{ CAC } & \multicolumn{1}{c}{0.05 Fe-MCAC } \\
\hline BET specific surface area $\left(\mathrm{m}^{2} / \mathrm{g}\right)$ & 686.06 & 1079.67 \\
Lamgmuir surface area $\left(\mathrm{m}^{2} / \mathrm{g}\right)$ & 1042.56 & 1689.73 \\
Mesopore surface area $\left(\mathrm{m}^{2} / \mathrm{g}\right)$ & 290.63 & 491.38 \\
Total pore volume $\left(\mathrm{cm}^{3} / \mathrm{g}\right)$ & 0.39 & 0.64 \\
Mesoporous pore volume $\left(\mathrm{cm}^{3} / \mathrm{g}\right)$ & 0.22 & 0.48 \\
\hline
\end{tabular}

269 3.2.4 Surface acidity and basicity of CAC and 0.05Fe-MCAC

270 The total acidity and basicity of the CAC and 0.05Fe-MCAC samples are summarized 271 in Table 2. The Fe-MCAC sample was more basic than those on its surface.

272 One likely reason was that $\mathrm{Fe}^{3+}$ was loaded onto the surface of $0.05 \mathrm{Fe}-\mathrm{MCAC}$, and oxygen 273 was removed; thus, the basicity properties were enhanced. The study by Rivera-Utrilla et al.

274 [27] showed that the increase in the basicity of AC surface favored the adsorption of organic 275 compounds. Strong basic properties of the 0.05Fe-MCAC sample were generally conducive 276 to PAHs adsorption from aqueous solutions. The amount of iron loading on the $277 \quad$ 0.05Fe-MCAC sample was $0.135 \mathrm{mmol} / \mathrm{g}$ (Table 2), which could be attributed to the changes 278 in the surface chemistry properties and increased the pore structure of the 0.05Fe-MCAC 

adsorption capacity for PAHs.

Table 2

Total acidic and total basicity of CAC and 0.05Fe-MCAC

\begin{tabular}{llll}
\hline Sample & Total acidity $(\mathrm{mmol} / \mathrm{g})$ & $\begin{array}{l}\text { Total basicity } \\
(\mathrm{mmol} / \mathrm{g})\end{array}$ & $\begin{array}{l}\text { Fe loading } \\
(\mathrm{mmol} / \mathrm{g})\end{array}$ \\
\hline CAC & 1.19 & 0.14 & - \\
$0.05 F e-M C A C$ & 0.54 & 3.59 & 0.135 \\
\hline
\end{tabular}

\subsection{Adsorption of PAHs on CAC and 0.05Fe-MCAC}

Fig. 7 shows that the CAC and 0.05Fe-MCAC samples for the adsorption of naphthalene, phenanthrene, and pyrene solutions at $20{ }^{\circ} \mathrm{C}$ had a similar result. After modification was performed, the 0.05Fe-MCAC sample yielded a higher adsorption capacity for naphthalene, phenanthrene, and pyrene solutions than the CAC sample. The enhanced adsorption capacity on the 0.05Fe-MCAC sample for naphthalene adsorption was the most evident; in this finding, the adsorption capacity increased by $66.07 \%$ (Fig. 7). In the same adsorption condition, the total adsorption capacity for PAHs on CAC and 0.05Fe-MCAC samples followed this order: pyrene $>$ phenanthrene $>$ naphthalene. Using petroleum-coke-derived porous carbon adsorption of PAHs from aqueous solutions, Yuan et al. [3] found that the adsorption capacity followed the same order in terms of adsorption capacity. A similar behavior was reported for the CAC adsorption for naphthalene, phenanthrene, and pyrene by Xiao et al [29]. Therefore, increasing the number of aromatic rings (or $\pi$-electrons) in the PAH compound could increase the adsorption capacity for PAHs from aqueous solutions. This phenomenon could be attributed to the fact that molecules with more aromatic rings show significantly higher adsorptive affinity than the aromatics with 

$\pi$-electrons of benzene rings and active sites on an AC surface [25, 29, 30]. In addition, the affinity of $0.05 \mathrm{Fe}-\mathrm{MCAC}$ to PAHs solution was greater than that of the other samples because of iron modification. However, given that the high-activity iron-modified CAC via microwave radiation provided the $0.05 \mathrm{Fe}-\mathrm{MCAC}$ sample with a developed pore structure and an enlarged pore size, we concluded that small-molecule PAHs could be easily adsorbed.

305 Thus, the 0.05Fe-MCAC sample had higher adsorption capacity of PAHs from aqueous solutions. Compared with the CAC, the 0.05Fe-MCAC sample is a promising adsorbent for PAHs from aqueous solution.

308

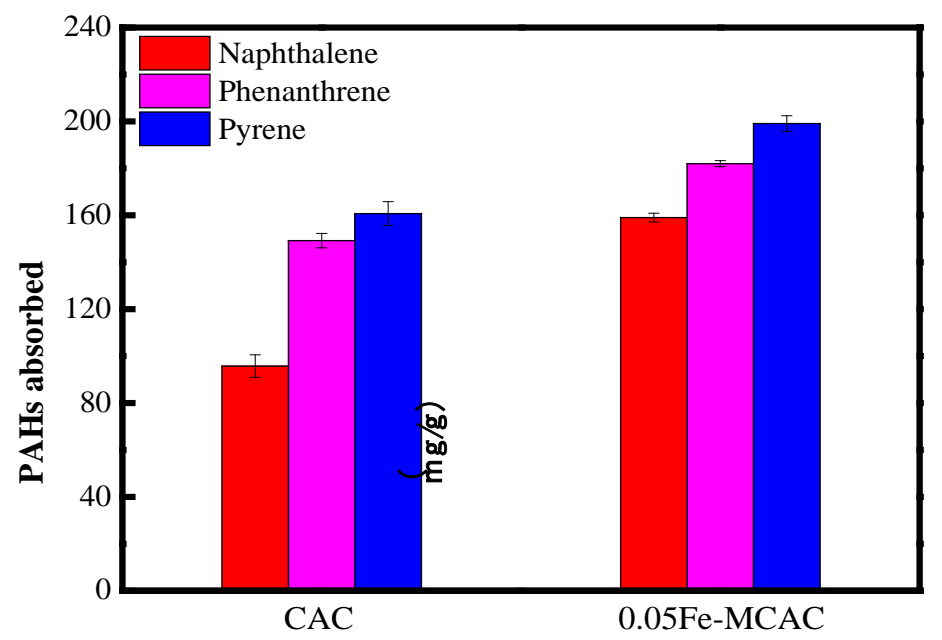

Fig. 7. Adsorption of PAHs on CAC and 0.05Fe-MCAC at $20{ }^{\circ} \mathrm{C}$

\subsection{Adsorption kinetics}

The adsorption mechanism (adsorbed physically, e.g., by a dispersive force) associated with the removal of PAHs on the surfaces of the CAC and 0.05Fe-MCAC samples was explained [31]. The adsorption kinetics results showed that the increase in temperature reduced the adsorption capacity of naphthalene, phenanthrene, and pyrene adsorbed onto CAC and 0.05Fe-MCAC (Figs. 8a-c). This result indicated that low temperature favored the 
adsorption of naphthalene, phenanthrene, and pyrene from aqueous solutions.

Fig. 8 shows that the adsorption of all PAHs appeared to have similar kinetic behavior

318 from $10{ }^{\circ} \mathrm{C}$ to $40{ }^{\circ} \mathrm{C}$. Adsorption involves two distinguished periods, namely, an initial 319 period of rapid adsorption and a period of slow adsorption [14, 32]. The initial adsorption 320 stage was short in the first 10 min; a gradual process occurred until equilibrium was attained 321 after a 40 min contact time; this finding indicated that the maximum sorption of naphthalene, 322 phenanthrene, and pyrene occurred for approximately 40 min (Fig. 8). The 0.05Fe-MCAC 323 sample adsorbed naphthalene, phenanthrene, and pyrene solutions to a greater extent than the 324 CAC sample. The adsorption process of PAHs on the 0.05Fe-MCAC sample was faster than 325 that on other materials [12, 33]. A 2 mg modified periodic mesoporous organosilica (PMO) 326 reached adsorption equilibrium for the adsorption of PAHs aqueous solutions (8 mg/L, $5 \mathrm{~mL})$ 327 for $24 \mathrm{~h}$ [12]. Using $0.5 \mathrm{~g}$ of an immature coal (leonardite) removed $100 \mu \mathrm{g} / \mathrm{L}$ of PAHs from 328 aqueous solutions, and equilibrium time was reached at $24 \mathrm{~h}$ [33]. Moreover, the economical 329 dosage of absorbents is a symbol to evaluate the adsorption efficiency. The dosage of the 330 0.05Fe-MCAC sample was $15 \mathrm{mg}$ in our study, which showed higher adsorption capacity and faster adsorption than those in previous studies [12, 33].
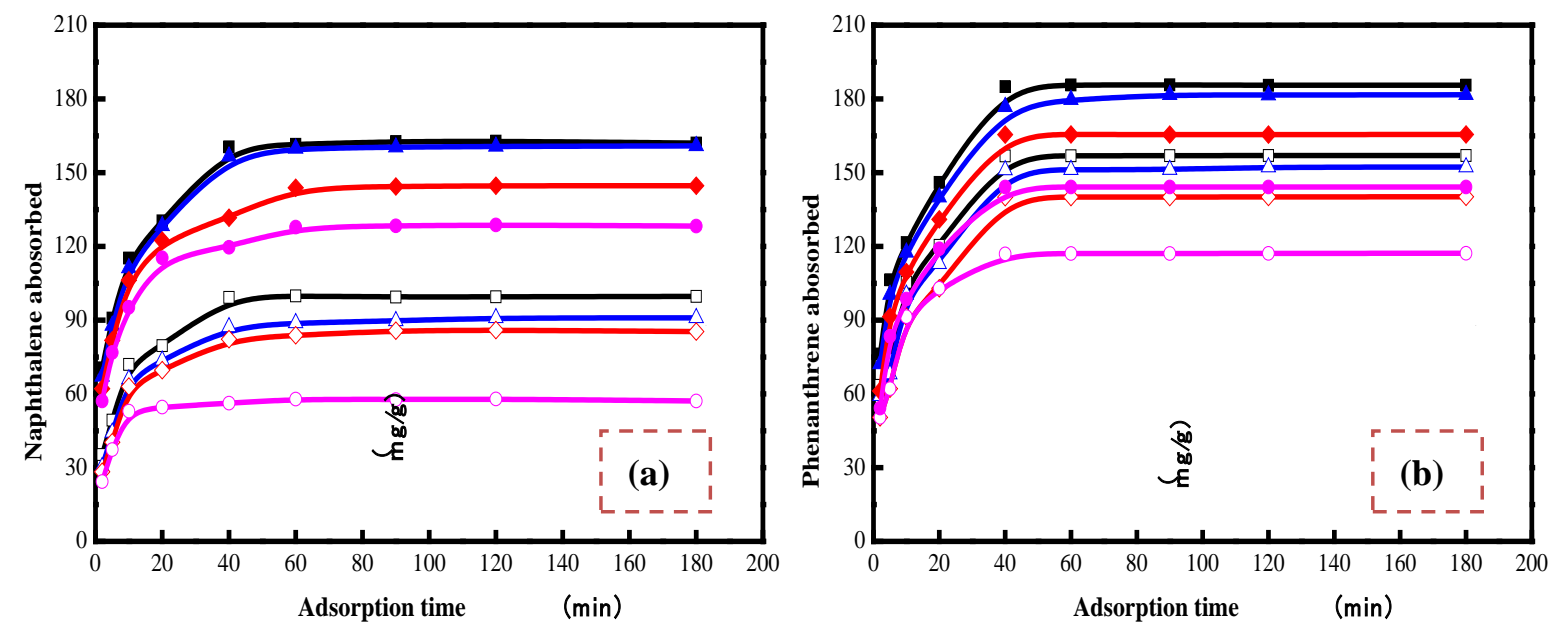


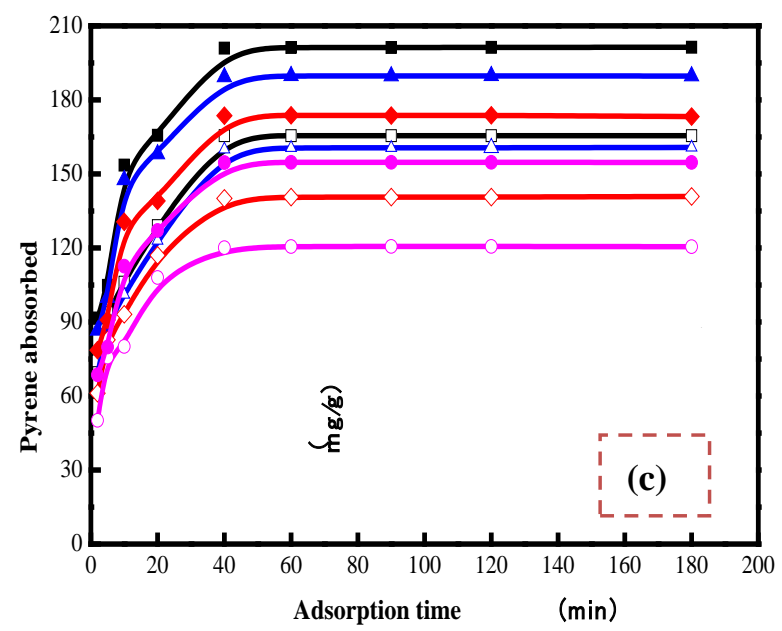

Fig. 8. Naphthalene (a), phenanthrene (b), and pyrene (c) on the CAC and 0.05Fe-MCAC kinetic curves at different temperature In order to evaluate the adsorption kinetics of naphthalene, phenanthrene, and pyrene on the CAC and 0.05Fe-MCAC samples, the pseudo first order and the pseudo second order

340 kinetic models were applied to the experimental data.

\subsubsection{Pseudo-first-order kinetics}

The pseudo-first-order kinetic rate equation is expressed as:

$343 \quad \frac{1}{q_{t}}=\frac{1}{q_{e}}+\frac{k_{1}}{q_{e} t}$

344 where $k_{1}$ is the rate constant of pseudo-first-order sorption (min). The first-order rate

345 constant can be determined from the slope of the linearized pseudo-first-order rate 346 equation.

Table 3 shows the quantity of naphthalene, phenanthrene, and pyrene adsorbed at equilibrium for each of the CAC and 0.05Fe-MCAC samples synthesized using the

349 pseudo-first-order model, constant kinetics, and a factor of correlation $R^{2}$ between 0.8870-0.9860. These values suggest the dispersion of the experimental data and show 
351 that the adsorption of naphthalene, phenanthrene, and pyrene on the CAC and

$352 \quad$ 0.05Fe-MCAC samples are not a first-order reaction.

353

$355 \quad \frac{t}{q_{t}}=\frac{1}{k_{2} q_{e}^{2}}+\frac{t}{q_{e}}$ model.

\subsubsection{Pseudo-second-order kinetics}

The pseudo-second-order kinetic rate equation is expressed as:

where $k_{2}$ is the rate constant of pseudo-second-order sorption $[\mathrm{g} /(\mathrm{mg} \cdot \mathrm{min})]$. The second-order rate constant can be determined from the intercept of the linearized pseudo-second-order rate equation.

The amounts of naphthalene, phenanthrene, and pyrene adsorbed in equilibrium at different temperatures, the velocity constant of the model, and the correlation factors were obtained from the linearization of the model (Table 3). The pseudo-second-order model from $10{ }^{\circ} \mathrm{C}$ to $40{ }^{\circ} \mathrm{C}$ all had good fit for the CAC and 0.05Fe-MCAC samples with high correlation coefficients $\left(R^{2}=0.9992-0.9997\right)$. The $q_{\exp }$ values in the pseudo-second-order model were closer to the experimental $q_{\text {cal }}$ values than the values in the pseudo-first-order model. This indicated the applicability of the second-order kinetic model to describe the adsorption processes of naphthalene, phenanthrene, and pyrene on the CAC and 0.05Fe-MCAC samples. This result also suggested that the adsorption process involved chemical adsorption $[14,20]$. We found that the 0.05Fe-MCAC sample had the best adsorption efficiency for naphthalene adsorption. From the literature, the adsorption of naphthalene on naturally and chemically modified bentonites [1] and the adsorption of PAHs on the CAC and modified CAC $[14,24]$ were best represented by the pseudo-second-order 
375 Arrhenius equation (4):

$376 \quad \ln k_{2}=\ln \mathrm{A}-\frac{\mathrm{E}_{a}}{\mathrm{R}}\left(\frac{1}{\mathrm{~T}}\right)$

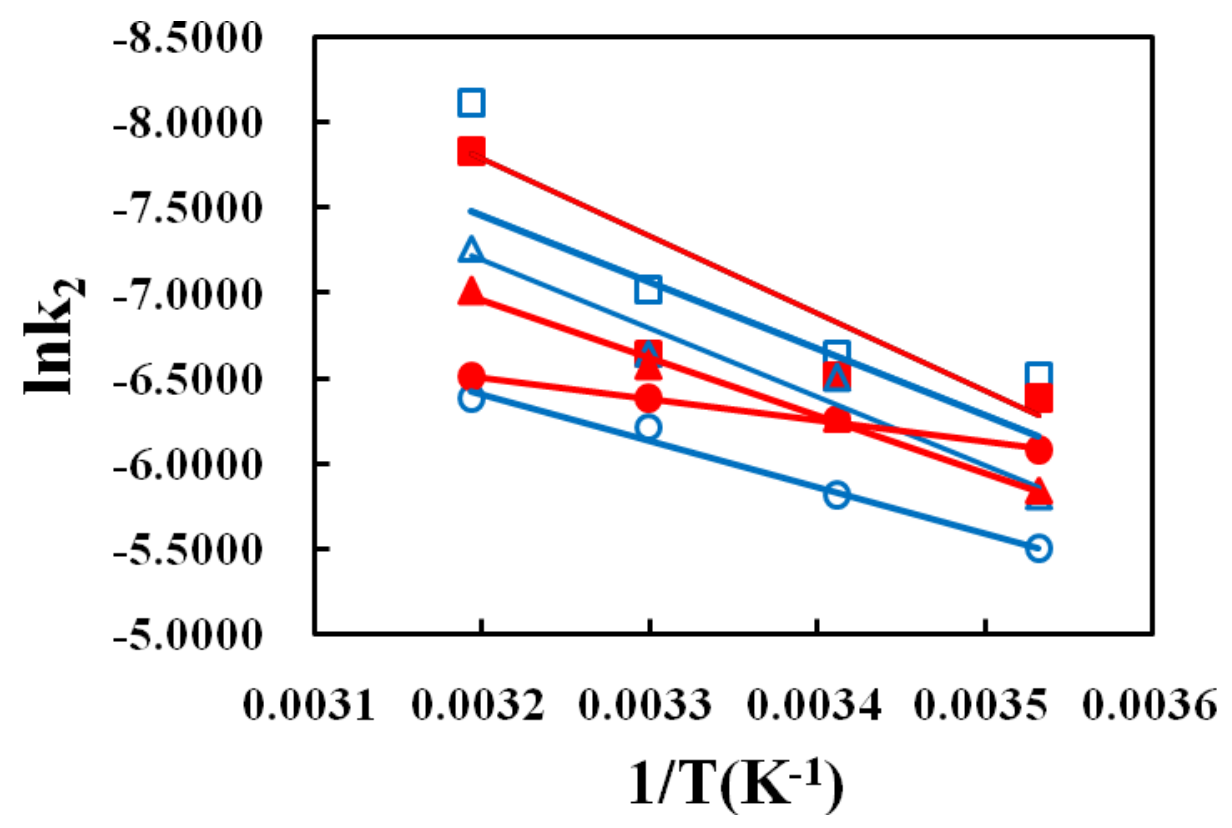

When $\ln k_{2}$ is plotted against the reciprocal of the temperature $(1 / T)$ as in Fig. 9, $E_{a}$ represents the slope shown in Table 3. We found that the modified sample had low activation energy for PAH adsorption, which may have improved the adsorption of PAH. Iron had a certain catalytic effect and enhanced the reaction rate. These low activation energy values of $E_{\mathrm{a}}(\leq 40 \mathrm{~kJ} / \mathrm{mol})$ for adsorption of PAHs on the carbon adsorbents were mainly mechanisms of physical adsorption [34].

387 Fig. 9. Plots of $\ln k_{2} / \mathrm{T}^{-1}$ for adsorption of naphthalene, phenanthrene and pyrene on CAC and 
390 Table 3 Kinetic models parameters for the adsorption of naphthalene, phenanthrene and 391 pyrene on CAC and 0.05Fe-MCAC

\begin{tabular}{|c|c|c|c|c|c|c|c|c|c|c|}
\hline \multirow[b]{2}{*}{ Adsorbates } & \multirow[b]{2}{*}{ Samples } & \multirow[b]{2}{*}{$\begin{array}{c}T \\
\left({ }^{\circ} \mathrm{C}\right)\end{array}$} & \multirow[b]{2}{*}{$\begin{array}{c}q_{\exp } \\
(\mathrm{mg} / \mathrm{g})\end{array}$} & \multicolumn{3}{|c|}{ Pseudo-first-order } & \multicolumn{3}{|c|}{ Pseudo-second-order } & \multirow[b]{2}{*}{$\begin{array}{c}E \mathrm{a} \\
(\mathrm{kJ} / \mathrm{mol})\end{array}$} \\
\hline & & & & $\begin{array}{c}q_{\mathrm{e}} \\
(\mathrm{mg} / \mathrm{g})\end{array}$ & $\begin{array}{c}k_{1} \\
\left(\min ^{-1}\right)\end{array}$ & $R^{2}$ & $\begin{array}{c}q_{\mathrm{e}} \\
(\mathrm{mg} / \mathrm{g})\end{array}$ & $\begin{array}{c}k_{2} \\
(\mathrm{~g} /(\mathrm{mg} \cdot \mathrm{mi} \\
\mathrm{n})\end{array}$ & $R^{2}$ & \\
\hline \multirow{8}{*}{ Naphthalene } & \multirow{4}{*}{ CAC } & 10 & 105.00 & 99.65 & 3.70 & 0.9660 & 109.11 & 0.0041 & 0.9997 & \multirow{4}{*}{22.36} \\
\hline & & 20 & 95.74 & 83.45 & 4.60 & 0.9790 & 95.98 & 0.0030 & 0.9992 & \\
\hline & & 30 & 85.94 & 79.91 & 4.45 & 0.9710 & 90.91 & 0.0020 & 0.9998 & \\
\hline & & 40 & 57.94 & 52.50 & 3.00 & 0.9840 & 58.82 & 0.0017 & 0.9994 & \\
\hline & \multirow{4}{*}{ 0.05Fe-MCAC } & 10 & 167.98 & 152.67 & 3.01 & 0.9490 & 169.04 & 0.0023 & 0.9993 & \multirow{4}{*}{10.23} \\
\hline & & 20 & 159.00 & 146.67 & 3.00 & 0.9490 & 162.67 & 0.0019 & 0.9995 & \\
\hline & & 30 & 144.68 & 132.86 & 2.71 & 0.9660 & 147.67 & 0.0017 & 0.9991 & \\
\hline & & 40 & 128.74 & 121.62 & 2.86 & 0.9750 & 132.86 & 0.0015 & 0.9995 & \\
\hline \multirow{8}{*}{ Phenanthrene } & \multirow{4}{*}{ CAC } & 10 & 160.96 & 142.86 & 2.71 & 0.8870 & 156.98 & 0.0030 & 0.9996 & \multirow{4}{*}{33.18} \\
\hline & & 20 & 149.20 & 130.86 & 3.40 & 0.9530 & 150.67 & 0.0015 & 0.9993 & \\
\hline & & 30 & 140.85 & 120.67 & 3.50 & 0.9770 & 144.32 & 0.0013 & 0.9995 & \\
\hline & & 40 & 117.20 & 110.43 & 3.00 & 0.9350 & 123.00 & 0.0007 & 0.9994 & \\
\hline & \multirow{4}{*}{ 0.05Fe-MCAC } & 10 & 190.43 & 157.78 & 3.14 & 0.8730 & 185.58 & 0.0029 & 0.9998 & \multirow{4}{*}{28.11} \\
\hline & & 20 & 181.99 & 173.47 & 3.71 & 0.9010 & 185.46 & 0.0019 & 0.9998 & \\
\hline & & 30 & 165.52 & 142.86 & 2.71 & 0.9450 & 166.67 & 0.0014 & 0.9992 & \\
\hline & & 40 & 144.18 & 126.67 & 3.83 & 0.9860 & 146.73 & 0.0009 & 0.9993 & \\
\hline \multirow{8}{*}{ Pyrene } & \multirow{5}{*}{ CAC } & 10 & 172.46 & 165.67 & 2.50 & 0.8970 & 169.50 & 0.0015 & 0.9993 & \multirow{4}{*}{38.75} \\
\hline & & 20 & 160.72 & 154.65 & 2.83 & 0.9020 & 163.32 & 0.0013 & 0.9994 & \\
\hline & & 30 & 140.85 & 132.86 & 2.71 & 0.9450 & 146.67 & 0.0009 & 0.9993 & \\
\hline & & 40 & 120.60 & 115.94 & 3.00 & 0.9860 & 124.00 & 0.0003 & 0.9992 & \\
\hline & & 10 & 201.32 & 193.45 & 2.60 & 0.8900 & 206.13 & 0.0017 & 0.9995 & \multirow{4}{*}{33.56} \\
\hline & \multirow{3}{*}{ 0.05Fe-MCAC } & 20 & 199.07 & 189.98 & 2.61 & 0.8990 & 200.32 & 0.0015 & 0.9996 & \\
\hline & & 30 & 173.25 & 163.94 & 3.00 & 0.8930 & 176.53 & 0.0013 & 0.9994 & \\
\hline & & 40 & 154.70 & 142.47 & 2.43 & 0.8980 & 156.32 & 0.0004 & 0.9993 & \\
\hline
\end{tabular}

\subsection{Regeneration of 0.05Fe-MCAC}

393 The results of regeneration studies are presented in Fig. 10. The 0.05Fe-MCAC sample

394 still had a high adsorption capacity for pyrene, which reached a level of $92.14 \%$ (183.43

$395 \mathrm{mg} / \mathrm{g}$ ) of the initial value after three cycles. This indicated that the modified sample had good 
stability, reusability, and adsorption effect for pyrene from aqueous solutions because the iron ion could exist in the surface structure of modified CAC in a stable form. The study reported by Shi et al. showed that naphthalene adsorption onto stable high-surface-area carbon still had high capacity after three cycles of alcohol treatment for the regeneration of the spent carbon [35].

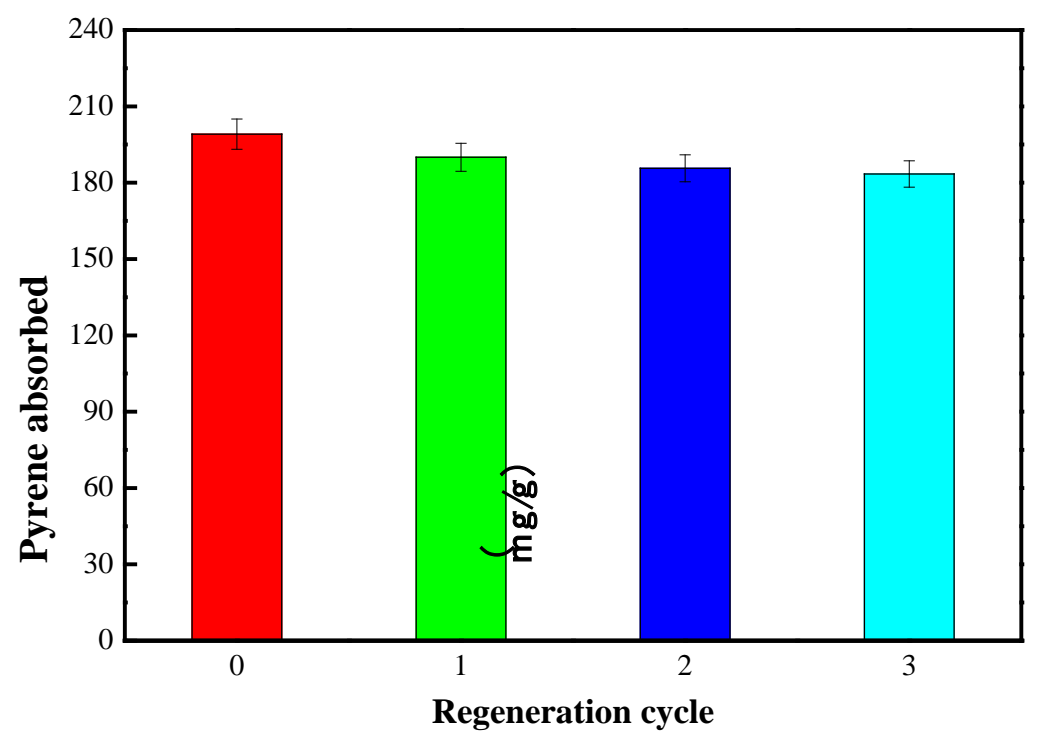

401

Fig.10. Adsorption capacities of pyrene onto 0.05Fe-MCAC for three cycles

\section{Conclusions}

CAC was modified with iron via microwave radiation. The obtained 0.05Fe-MCAC sample was characterized through SEM, FTIR, surface acidity and basicity, and nitrogen adsorption-desorption methods. The surface chemistry and textural properties of CAC changed when it was modified by iron nitrate via microwave radiation. The developed pore structure, increased surface area, improved basic properties, and reduced oxygen-containing groups favored PAHs adsorption from aqueous solutions. The modified sample (0.05Fe-MCAC) yielded a high adsorption capacity of $160.88 \mathrm{mg} / \mathrm{g}$ for naphthalene, 181.99 mg/g for phenanthrene, and $199.07 \mathrm{mg} / \mathrm{g}$ for pyrene. Among our observations, the increase 
412 in the adsorption capacity of naphthalene on the 0.05Fe-MCAC sample was the most evident.

413 The modified sample was greater extent and more rapid for adsorbing naphthalene with less

414 aromatic rings than the CAC. Kinetic studies exhibited a faster adsorption rate of PAHs on

415 the 0.05Fe-MCAC sample than the CAC. The pseudo-second-order model fitted well for

416 CAC and 0.05Fe-MCAC samples. Low temperature is favorable for the adsorption of

417 naphthalene, phenanthrene, and pyrene from aqueous solutions. The modified

418 0.05Fe-MCAC exhibited lower activation energy for the adsorption of naphthalene, 419 phenanthrene, and pyrene solutions that that of CAC. The CAC modified with iron nitrate 420 via microwave radiation was an efficient adsorbent of PAHs from aqueous solutions. The 421 modified sample also showed good stability and reusability for the adsorption of PAHs in 422 solutions. Thus, the CAC sample modified via a simple treatment is a very effective sorbent.

424 Acknowledgments

This work was supported financially by funding from the National Natural Science

Foundation of China (51262025) and International scientific and technological cooperation project of Xinjiang Bingtuan (2013BC002).

References

[1] Kaya EMO, Ozcan AS, Gok O, Ozcan A. Adsorption kinetics and isotherm parameters of naphthalene onto natural- and chemically modified bentonite from aqueous solutions. Adsorption 2013; 19: 879-888.

[2] Tran-Duc T, Thamwattana N, Cox BJ, Hill JM. Adsorption of polycyclic aromatic hydrocarbons on graphite surfaces. Com Mater Sci 2010; 49: 307-312.

[3] Yuan MJ, Tong ST, Zhao SQ, Jia CQ. Adsorption of polycyclic aromatic hydrocarbons 
from water using petroleum coke-derived porous carbon. J Hazard Mater 2010; 181: 1115-1120.

[4] Cai S, Syage JA, Hanold KA, Balogh MP. Ultra performance liquid chromatography-atmospheric pressure photoionization tandem mass spectrometry for high-sensitivity and high-throughput analysis of U.S. environmental protection agency 16 priority pollutants polynuclear aromatic hydrocarbons. Anal Chem 2009; 81: 2123-2128.

[5] Valderrama C, Gamisans X, De las Heras X, Farran A, Cortina JL. Sorption kinetics of polycyclic aromatic hydrocarbons removal using granular activated carbon: Intraparticle diffusion coefficients. J Hazard Mater 2008; 157: 386-396.

[6] Xiao XM, Tian F, Yan YJ, Wu ZS, Adsorption behavior of pyrene from onto coal-based activated carbons prepared by microwave activation. J Shihezi Univ 2014; 32: 485-490.

[7] Ge XY, Wu ZS, Yan YJ, Zeng YX, The ammonia modification of coal-based activated carbon and its pyrene adsorption performance in aqueous solution. J Shihezi Univ 2016; 34: 92-99.

[8] Huang LH, Sun YY, Wang WL, Yue QY, Yang T. Comparative study on characterization of activated carbons prepared by microwave and conventional heating methods and application in removal of oxytetracycline (OTC). Chem Eng J 2011; 171: 1446-1453.

[9] Liu QS, Zheng T, Li N, Wang P, Abulikemu G. Modification of bamboo-based activated carbon using microwave radiation and its effects on the adsorption of methylene blue. Appl Surf Sci 2010; 256: 3309-3315.

[10] Shaarani FW, Hameed BH. Ammonia-modified activated carbon for the adsorption of 2, 4-dichlorophenol. Chem Eng J 2011; 169: 180-185.

[11]Yin CY, Aroua MK, Daud WMAW. Review of modifications of activated carbon for enhancing contaminant uptakes from aqueous solutions. Sep Purify Technol 2007; 52: 403-415.

[12]Vidal CB, Barros AL, Moura CP, De Lima ACA, Dias FS, Vasconcellos LCG, Fechine PBA, Nascimento RF. Adsorption of polycyclic aromatic hydrocarbons from aqueous solutions by modified periodic mesoporous organosilica. J Colloid Interf Sci 2011; 357: 466-473. 
[13]Chen BL, Yuan MX, Liu H. Removal of polycyclic aromatic hydrocarbons from aqueous solution using plant residue materials as a biosorbent. J Hazard Mater 2011; 188: 436-442.

[14]Ge XY, Tian F, Wu ZL, Yan YJ, Cravotto G, Wu ZS. Adsorption of naphthalene from aqueous solution on coal-based activated carbon modified by microwave induction: microwave power effects. Chem Eng Process 2015; 91: 67-77.

[15]Moreno-Piraján JC, Tirano J, Salamanca B, Giraldo L. Activated carbon modified with copper for adsorption of propanethiol. Int J Mol Sci 2010; 11: 927-942.

[16]Bhatnagar A, Hogland W, Marques M, Sillanpää M. An overview of the modification methods of activated carbon for its water treatment applications. Chem Eng J 2013; 219: 499-511.

[17]Moreno-Piraján JC, Giraldo L. Activated carbon from bamboo waste modified with iron and its application in the study of the adsorption of arsenite and arsenate. Cent Eur J Chem 2013; 11: 160-170.

[18]Sun ZM, Yu YC, Pang SY, Du DY. Manganese-modified activated carbon fiber (Mn-ACF): Novel efficient adsorbent for Arsenic. App Surf Sci 2013; 284: 100-106.

[19]De M, Azargohar R, Dalai AK, Shewchuk SR. Mercury removal by bio-char based modified activated carbons. Fuel 2013; 103: 570-578.

[20]Chen WF, Parette R, Zou JY, Cannon FS, Dempsey BA, Arsenic removal by iron-modified activated carbon. Water Res 2007; 41: 1851-1858.

[21]Xiao XM, Tian F, Yan YJ, Wu ZS, Wu ZL, Cravotto G. Adsorption behavior of phenanthrene onto coal-based activated carbon prepared by microwave activation. Korean J Chem Eng 2015; 32: 1129-1136.

[22]Song XL, Liu HY, Cheng L, Qu YX. Surface modification of coconut-based activated carbon by liquid-phase oxidation and its effects on lead ion adsorption. Desalination 2010; 255: 78-83.

[23]Foo KY, Hameed BH, Microwave-assisted preparation and adsorption performance of activated carbon from biodiesel industry solid reside: Influence of operational parameters. Bioresource Technol 2012; 103: 398-404.

[24]Foo KY, Hameed BH, Potential of jackfruit peel as precursor for activated carbon 
prepared by microwave induced $\mathrm{NaOH}$ activation. Bioresource Technol 2012; 112: $143-150$.

[25]Ge XY, Ma XF, Wu ZS, Xiao XM, Yan YJ. Modification of coal-based activated carbon

with nitric acid using microwave radiation for adsorption of phenanthrene and naphthalene. Res Chem Intermediat 2014; 41: 7327-7347.

[26]Liu QS, Zheng T, Li N, Wang P, Abulikemu G. Modification of bamboo-based activated carbon using microwave radiation and its effects on the adsorption of methylene blue. Appl Surf Sci 2010; 256: 3309-3315.

[27]Rivera-Utrilla J, Sánchez-Polo M, Gómez-Serrano V, Álvarez PM, Alvim-Ferraz MCM, Dias JM. Activated carbon modifications to enhance its water treatment applications. An overview. J Hazard Mater 2011; 187: 1-23.

[28]Ponvel KM, Kavitha D, Kim KM, Lee CH. Adsorption of 2, 4-dichlorophenol on metal-nitrate modified activated carbon. Korean J Chem Eng 2009; 26: 1379-1382.

[29]Xiao XM, Liu DD, Yan YJ, Wu ZL, Wu ZS, Cravotto G. Preparation of activated carbon from Xinjiang region coal by microwave activation and its application in naphthalene, phenanthrene, and pyrene adsorption. J Taiwan Inst Chem Eng 2015; 53: 160-167.

[30]Dowaidar AM, EI-Shahawi MS, Ashour I. Adsorption of polycyclic aromatic hydrocarbons onto activated carbon from non-aqueous media: the influence of the organic solvent polarity. Sep Sci Technol 2007; 42: 3609-3622.

[31]Valderrama C, Cortina JL, Farran A, Gamisans X, Lao CJ. Kinetics of sorption of polyaromatic hydrocarbons onto granular activated carbon and macronet hyper-cross-linked polymers (MN200). Colloid Inter Sci 2007; 310: 35-46.

[32] Ania CO, Cabal B, Pevida C, Arenillas A, Parra JB, Rubiera F, Pis JJ. Removal of naphthalene from aqueous solution on chemically modified activated carbons. Water Res 2007; 41: 333-340.

[33]Zeledon-Toruno ZC, Lao-Luque C, De las Heras FXC, Sole-Sardans M. Removal of PAHs from water using an immature coal (leonardite). Chemosphere 2007; 67: 505-512.

[34]Chen Y, Jiang WJ, Jiang L, Ji XJ. Adsorption behavior of activated carbon derived from pyrolusite-modified sewage sludge: equilibrium modeling, kinetic and thermodynamic 

studies, Water Sci Technol 2011; 64: 661-669.

526 [35] Shi QQ, Li AM, Zhu ZL, Liu B. Adsorption of naphthalene onto a high-surface-area 527 carbon from waste ion exchange resin. J Environ Sci China 2013; 25: 188-194. 